\title{
The incidence of scarlet fever
}

\author{
By ELIZABETH M. PERKS AND RICHARD T. MAYON-WHITE \\ Microbiology Department, John Radcliffe Hospital, Oxford
}

(Received 26 May 1983; accepted 20 June 1983)

\begin{abstract}
SUMMARY
This study attempted to find the incidence of scarlet fever in the Oxford region, including the proportion of patients from whom Streptococcus pyogenes could be isolated. General practitioners collected throat swabs from patients with suspected scarlet fever. The swabs were examined for viral and bacterial pathogens. Children admitted to hospital were used as controls. Twenty-five of 105 patients with suspected scarlet fever grew Str. pyogenes; M type 4 was the commonest type. The clinical diagnosis of scarlet fever was not always confirmed by throat culture. The annual incidence of scarlet fever was estimated to be 0.3 cases per 1000 per year.
\end{abstract}

\section{INTRODUCTION}

Scarlet fever was once a severe life-threatening infection for which the clinical diagnosis was relatively easy. In modern times the illness is generally mild and uncommon and may be confused with other febrile rashes. The accuracy of notifications and reports from sentinel practices is uncertain. The present study was designed to find the current incidence of scarle fever, and the proportion of patients from whom Streptococcus pyogenes could be isolated.

In the Oxford region there is a sentinel practice scheme in which a proportion of clinical diagnoses are checked by laboratory tests. The present study was started because some practices had observed a rise in the incidence of illness resembling scarlet fever.

\section{METHODS}

Eighteen sentinel practices agreed to enter patients with suspected scarlet fever into the study from July 1981 to June 1982 . Suspected scarlet fever was defined as a diffuse erythematous rash with symptoms of upper respiratory tract infection or fever.

Virological and bacteriological throat cultures were obtained from patients with suspected scarlet fever. Doctors were requested to sweep a double swab across the tonsils (or the tonsillar fossar in tonsillectomized patients). One swab was then broken into a streptococcal transport medium, serum glucose agar (SGA) (Colling et al. 1980) and the other into viral transport medium (single strength Eagle's minimal essential medium (Wellcome) supplemented with lactalbumin, bicarbonate and neomycin). The presence of the following symptoms was recorded on the laboratory request form: typical rash, sore throat, coryza, raised or tender cervical glands and temperature greater than $37.5^{\circ} \mathrm{C}$. Information was collected about drug 
therapy and the age and sex of the patient. Patients with a confident diagnosis of scarlet fever were recorded as part of the long-term morbidity survey in the sentinel practices.

The swab in SGA was inoculated on to $5 \%$ horse blood agar, incubated aerobically and anaerobically overnight at $37^{\circ} \mathrm{C}$. Colonies of $\beta$-haemolytic streptococci were grouped by Lancefield's method (Lancefield, 1933). Group A streptococci were typed for M and T antigens (Lancefield, 1928; Griffith, 1934). Other organisms were identified by standard bacteriological techniques. Isolates of Staphylococcus aureus were phage typed. The aerobic blood agar was incubated for a further $24 \mathrm{~h}$ and examined for the presence of Corynebacterium haemolyticum.

The specimen in viral transport medium was inoculated into the following cell lines: MRC 5 (fibroblast), baboon kidney (Centre for Applied Microbiology and Research, Porton) and Hep 2. The tissue culture tubes were rolled at $34{ }^{\circ} \mathrm{C}$ for 14 days and examined regularly for the presence of cytopathic effects (CPE). If no CPE was seen by the end of the incubation period, the baboon kidney cell line was examined for haemadsorbing viruses, using $1 \%$ guinea-pig erythrocytes. An RK13 cell line was included for any patient with raised cervical glands and any patient with suspected rubella. This was rolled at $34{ }^{\circ} \mathrm{C}$ for 10 days and then passaged at weekly intervals for 3 weeks.

The isolation of pathogenic organisms from the patients with suspected scarlet fever was compared with the results of throat swabs taken in the same way from children admitted to the John Radcliffe Hospital from the same area in the same period. None of these 'control' children had suspected scarlet fever. The types of Str. pyogenes isolated from patients with scarlet fever were compared with types from patients with pharyngitis diagnosed by routine throat cultures.

During the year of study, three children were admitted to the John Radcliffe Hospital with suspected scarlet fever. Their clinical and bacteriological findings were added to those from general practice.

\section{RESULTS}

In the study period, 105 patients with suspected scarlet fever were examined. The majority of patients $(63 \%)$ were children under 10 years old; 25 were adults. Given that every patient had a rash, the commonest clinical feature was a sore throat ( $71 \%$ of patients). The rash was thought to be typical of scarlet fever in $41(39 \%)$ patients. Fifty-eight $(55 \%)$ patients had cervical lymphadenopathy, 53 $(50 \%)$ had temperatures above $37.5{ }^{\circ} \mathrm{C}$ and $44(42 \%)$ had coryza. The full set of features of scarlet fever (typical rash, fever, sore throat, lymphadenopathy and absence of coryza) was present in only twelve patients.

Str. pyogenes was isolated from the throat swabs of 25 patients and was the commonest pathogen found. The isolation of Str. pyogenes was significantly more frequent in patients with a typical rash and those who had the full set of features listed above (Fig. 1). Two of the 71 control patients had Str. pyogenes. None of the patients aged over 15 years had symptoms typical of scarlet fever and only one grew a group A streptococcus.

Four of the patients with suspected scarlet fever had viruses which are known to cause rashes: three had echovirus type 9 and one had rubella virus grown from throat swabs. 
Number of patients

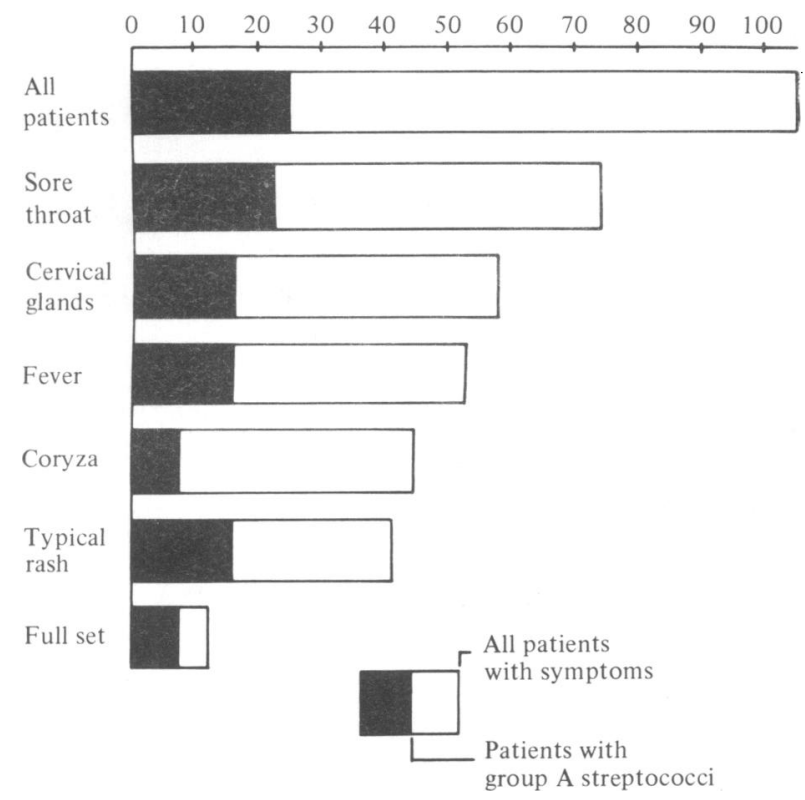

Fig. 1. The frequency of clinical features and isolation of group A streptococci.

Table 1. Other pathogens isolated in study

$\begin{array}{lcc} & \begin{array}{c}\text { 'Scarlet fever' } \\ \text { patients }\end{array} & \text { Controls } \\ \text { Group C and G streptococci } & 2 & 1 \\ \text { Staphylococcus aureus } & 3 & 3 \\ \text { Candida albicans } & 1 & 0 \\ \text { Echovirus } & 0 & \\ \quad \text { type } 7 & 3 & 1 \\ \text { type } 9 & 0 & 0 \\ \text { type 17 } & 1 & 1 \\ \text { Herpes simplex virus } & 2 & 0 \\ \text { Influenza B virus } & 1 & 0 \\ \text { Rhinovirus } & 0 & 0 \\ \text { Respiratory syncytial virus } & 1 & 1 \\ \text { Rubella virus } & 105 & 0 \\ \text { Number of patients studied } & & 71\end{array}$

A miscellany of other pathogens were isolated in similar numbers from both patients and controls (Table 1). The isolates of $S$. aureus each belonged to a different phage type and all were in phage group 3 . There was no isolate of C. haemolyticum from the re-incubated cultures.

The strains of Str. pyogenes isolated in the study belonged to five $\mathbf{M}$ types. The commonest types were $M$ type 4 with $12(48 \%)$ isolates and $M$ type 3 with $5(20 \%)$ (Table 2). These types were not found in the children in hospital with other conditions and were relatively less common in patients with uncomplicated pharyngitis. $M$ type 4 occurred in the autumn with a peak in November in both scarlet fever and uncomplicated pharyngitis patients. M type 3 was commonest in the second half of the period of study, with a peak in April. 
Table 2. $M$ types of Str. pyogenes in scarlet fever and uncomplicated pharyngitis (Numbers (and percentages) of strains)

$\begin{array}{cc}\text { M type } & \text { Scarlet fever patients } \\ 1 & 2(8 \%) \\ 3 & 5(20 \%) \\ 4 & 12(48 \%) \\ 6 & 3(12 \%) \\ 22 & 3(12 \%) \\ \text { Others } & 0 \\ \text { Total } & 25(100 \%)\end{array}$

Uncomplicated pharyngitis
patients
$48(5 \%)$
$153(15 \%)$
$161(16 \%)$
$113(11 \%)$
$139(14 \%)$
$374(39 \%)$
$988(100 \%)$

Two patients with suspected scarlet fever had Str. pyogenes $M$ type 4 and a second pathogen. A two-year-old boy had a 'typical' rash, sore throat, coryza and fever; he had a heavy growth of Str. pyogenes and influenza B virus. A six-year-old girl with a typical rash, sore throat and fever had a heavy growth of $S$. aureus and a light growth of Str. pyogenes.

During the year, three practices stopped keeping records of incidence. The twenty-two patients from these practices and the three admitted to hospital were excluded from the analysis of incidence. Hence 80 patients with suspected scarlet fever came from an observed population of 63796 , giving an overall rate of 1.25 cases per 1000 per year. The rate of clinical diagnosis of scarlet fever was $0 \cdot 25$ cases per 1000 per year, and the rate for bacteriologically confirmed cases was $0 \cdot 14$ per 1000 per year. If scarlet fever were defined as a rash with a positive streptococcal throat culture, the incidence in our study was $0 \cdot 3 / 1000 /$ year.

\section{DISCUSSION}

The finding that Str. pyogenes was isolated from $24 \%$ of scarlet fever patients, compared with $3 \%$ of the controls, suggests that clinical 'scarlet fever' is still a streptococcal disease. The close association of $M$ types 3 and 4 with scarlet fever was described by Parker (1967). Gunn \& Griffith (1928) observed that M types 1 and 6 caused more severe scarlet fever. Although the numbers in our study were small, we noticed that three of five patients with $M$ types 1 and 6 were referred to hospital.

The rash of scarlet fever is thought to be due to a delayed-type hypersensitivity reaction to an erythrogenic toxin which is present in most strains of Str. pyogenes (Kim \& Watson, 1972; Alouf, 1980). The association between certain $M$ types and scarlet fever remains to be explained. It is possible that these types may either produce more toxin or make enzymes which increase the penetration and action of the toxin. The occurrence of different types in the more severe cases supports this hypothesis.

It is possible that the mildness of present-day scarlet fever is due to its association with strains of lower pathogenicity than those of 100 years ago. However, the evidence on this point is missing. The resistance of children to severe streptococcal infection has probably increased, due to factors like improvements in living conditions and nutrition.

Given the association of certain types of group A streptococci with scarlet fever, 
the incidence of scarlet fever would be expected to follow the prevalence of these types. The epidemic patterns of $M$ type 3 and 4 have been studied in Oxfordshire and were found to fluctuate in incidence with a cycle of five to six years (Mayon-White \& Perks, 1982). This may partly explain why doctors notice scarlet fever re-appearing after several years of absence.

In studies of streptococcal pharyngitis there has been poor correlation between symptoms and laboratory results (Kaplan, 1972). The presence of a scarlatiniform rash is considered highly diagnostic of streptococcal infection (Wannamaker, 1972; Stillerman \& Bernstein, 1961). In our study a typical rash was the only symptom significantly associated with the isolation of Str. pyogenes. The results showed that present-day scarlet fever may be difficult to diagnose; only half of the patients with a rash typical of scarlet fever had a positive culture and nine isolates were from patients with atypical rashes. The combination of symptoms in a typical case of scarlet fever is a scarlatiniform rash, acute sore throat, raised temperature, cervical glands and absence of coryza. Such typical cases now appear to be rare, as only twelve of the 105 patients had this combination of symptoms.

C. haemolyticum and S. aureus phage groups 1 and 2 have been reported to cause 'scarlet fever' (Fell, Nagington \& Naylor, 1977; Feldman, 1961 ; Schlievert, 1981). There was no isolate of $C$. haemolyticum, and the three isolates of $S$. aureus did not belong to phage groups 1 and 2. Group C and G streptococci and Candida albicans may be carried in the normal throat. Although they occasionally cause pharyngitis, they do not cause rashes. The three isolates of echovirus type 9 were significant. An association of echovirus type 9 with erythematous and rubelliform rashes has been described (Lerner et al. 1963). None of the three patients with this virus had a sore throat or a typical scarlatiniform rash and so differed clinically from those with streptococcal infections. Of the remaining five viral isolates, only rubella is recognized to cause rashes. The rhinovirus, herpes simplex virus and influenza B probably represent concurrent infection and were not directly the cause of the patients' rashes.

The survey relied on the isolation of pathogens from single throat swabs. Failure of correct diagnosis may be of two types. Firstly, false positive isolations of Str. pyogenes may occur in streptococcal carriers, and patients with pharyngitis and concomitant rash. Secondly, false negative results (failure to isolate the pathogen) may occur if the patient has been treated with antibiotics, if the numbers of organisms present are low, if cell-death has occurred in transit, or if the swab was not taken correctly. The greatest source of error may have been in the collection of specimens. It was important to use both sides of the double swab, which was difficult in an unco-operative and sick child.

Failure to isolate viruses may have been more common. Viruses are excreted in greatest numbers in the prodromal phase of the illness. By the time of consultation they may be uncommon or absent from the throat.

It is accepted that serology could have detected more cases of infection. In another study the isolation rate from all exanthems (including hand, foot and mouth disease) was 16/76 and serological evidence of infection occurred in 39/76 patients (Cherry \& Jahn, 1966). Serology was not done in this study because most of the patients were young children and convalescent specimens would have increased the general practice work.

The diagnosis remains undetermined in patients from whom no bacterium or 


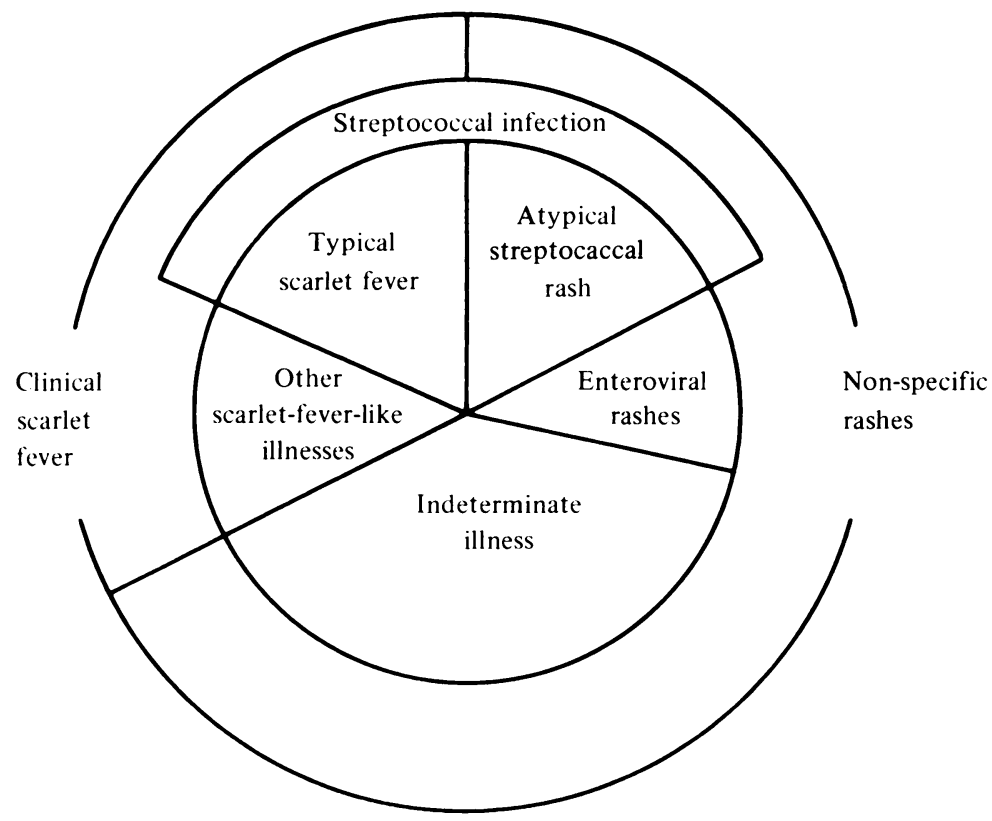

Fig. 2. Diagnoses of patients with a rash, fever and upper respiratory symptoms (excluding measles and rubella), shown in proportion to the findings of this study.

virus was found. They may have had organisms not investigated in this study, for example Mycoplasma pneumoniae and Epstein Barr virus. The possible nonmicrobial causes included 'heat rashes' and drugs and other hypersensitivity reactions.

Our original objective to find the incidence of scarlet fever proved more difficult than expected because the clinical and microbiological syndromes overlap (Fig. 2). Because few of the cases diagnosed clinically as scarlet fever had a typical rash, the correlation between symptoms and microbiological results was unclear. The total number of patients entered into the study over-estimates the incidence; many were not confirmed bacteriologically. But the number of culture-positive reported cases would probably give an under-estimate $(0 \cdot 14$ cases/1000/year) because atypical clinical cases and patients with false-negative cultures would be excluded. Our best estimate, namely 0.3 cases $/ 1000 /$ year, is derived from the total number of patients with a rash plus upper respiratory symptoms or a fever and group A streptococei in throat cultures.

The Birmingham Research Unit of the Royal College of General Practitioners publishes the incidence of scarlet fever in $\mathbf{4 0}$ general practices. In the most recent report (Office of Population Censuses and Surveys, 1982), the average weekly incidences for 1978,1979 and 1980 were $2 \cdot 0,2 \cdot 8$ and $1 \cdot 9$ cases/100000 respectively. These rates are equivalent to $1.04,1.45$ and 0.99 cases/1000/year. They are in the same range as the rate of suspected searlet fever recorded by the sentinel practices in the Oxford region (namely, $1 \cdot 25$ cases/1000/year). This similarity suggests that the incidence of scarlet fever observed in our study occurs elsewhere. 
We thank P. N. J. Appleton, J. F. P. Asbury, R. W. Ballantyne, E. Bark-Jones, E. M. Bridger, M. Britton, B. J. Brook, K. W. Burch, G. H. Fowler, T. G. Jones, G. C. Kassianos, P. Kersley, M. J. Knightley, R. Lloyd, J. M. Lloyd-Parry, B. McAvoy, D. N. MacLennan, A. MacPherson, A. C. Markus, P. Markus, G. Mason, P. H. Middleton, B. L. Neal, B. D. O'Farrell, R. Sharpley, J. R. Simpson, R. A. E. Spilling, T. I. Stewart, E. T. Tewson, J. Tewson, P. J. C. Trenchard, P. D. Wharin and A. R. Wilson for their help in the Regional Surveillance Project, and their practice nurses for collecting specimens. We are grateful to Mr I. Chinn and Mr C. Saunders for technical assistance. The Regional Surveillance Project is funded by an N.H.S. locally organized research grant. This study formed part of an MSc. degree at the University of Surrey awarded to E. M. Perks.

\section{REFERENCES}

Alouf, J. E. (1980). Streptococcal toxins (streptolysin O, streptolysin S, erythrogenic toxin). Pharmacology and Therapeutics 11, 661-717.

Cherry, J. D. \& JAHN, C. L. (1966). Virologic studies of exanthems. Journal of Paediatrics 68 , 204-214.

Colling, A., Kerr, I., Maxted, W. R. \& Widdowson, J. P. (1980). Streptococcal infection in a junior detention centre: a five year study. Journal of Hygiene 85, 331-341.

Feldman, C. A. (1961). Staphylococcal scarlet fever. New England Journal of Medicine 267, 877-878.

Fell, H. W. K., Nagington, J. \& Naylor, J. R. E. (1977). Corynebacterium haemolyticum infections in Cambridgeshire. Journal of Hygiene 79, 269-274.

GRIFFITH, F. (1934). The serological classification of Streptococcus pyogenes. Journal of Hygiene 34, 542-584.

GunN, W. \& Griffith, F. (1928). Bacteriological and clinical study of one hundred cases of scarlet fever. Journal of Hygiene 28, 250-266.

KaPLAN, E. L. (1972). Unresolved problems in diagnosis and epidemiology of streptococcal infection. In Streptococci and Streptococcal Diseases (ed. L. W. Wannamaker and J. M. Matsen), pp. 557-570. London: Academic Press.

KIM, Y. B. \& WATSON, D. W. (1972). Streptococcal exotoxins: biological and pathological properties. In Streptococciand Streptococcal Diseases (ed. L. W. Wannamaker and J. M. Matsen), pp. 34-50. London: Academic Press.

LANCEFIELD, R. C. (1928). The antigenic complex of Streptococcus haemolyticus. I. Demonstration of a type specific substance in extracts of Streptococcus haemolyticus. Journal of Experimental Medicine 47, 91-103.

LANCEFIELD, R. C. (1933). A serological differentiation of human and other groups of haemolytic streptococci. Journal of Experimental Medicine 57, 571-595.

Lerner, A. M., Klein, J. O., Cherry, J. D. \& Finland, M. (1963). New viral exanthems. New England Journal of Medicine 269, (part 1) 678-685 and (part 2) 736-740.

Mayon-White, R. T. \& Perks, E. M. (1982). Why type streptococci? The epidemiology of group A streptococci in Oxfordshire 1976-1980. Journal of Hygiene 88, 439-452.

Office of Population Census and Surveys. Communicable Disease Surveillance Centre of the Public Health Laboratory Service (1982). In Communicable Disease Statistics, 1980. London: HMSO.

PARKER, M. T. (1967). International survey of the distribution of serotypes of Streptococcus pyogenes (group A streptococci). Bulletin of the World Health Organisation 37, 513-527.

SCHLIEverT, P. M. (1981). Staphylococcal scarlet fever: role of pyrogenic exotoxins. Infection and Immunity 31, 732-736.

Stillerman, M. \& Bernstein, S. H. (1961). Streptococcal pharyngitis: evaluation of clinical symptoms in diagnosis. American Journal of Diseases of Children 101, 476-489.

Wannamaker, L. W. (1972). Perplexity and precision in the diagnosis of streptococcal pharyngitis. American Journal of Diseases of Children 124, 352-358. 